\title{
Supply Chains als Terra incognita für Controller?
}

\section{Liebe Leserinnen und Leser,}

Controller haben in den vergangenen Jahren ihren Aufgabenbereich deutlich ausgeweitet: Von der traditionellen finanziellen beziehungsweise erfolgswirtschaftlichen Perspektive des Gesamtunternehmens ausgehend, sind sie in immer mehr Bereiche des Unternehmens vorgedrungen. Studienergebnisse des WHU Controllerpanels zeichnen ein eindrucksvolles Bild: Es gibt Controlling-Spezialisierungen in den Bereichen Vertrieb, Produktion, Strategie, Human Resources und Einkauf - kein wichtiger Unternehmensbereich fehlt. Selbst ein so neues Feld wie Nachhaltigkeit findet zumindest in Großunternehmen zunehmend das Interesse von Controllern. Die Logistik ist in dieser Liste zwar ebenfalls vertreten, aber ihre Bedeutung ist über die Jahre gering geblieben und nicht gestiegen - ganz im Gegensatz etwa zum Vertriebs- oder zum Einkaufs-Controlling.

Dies wird der hohen Bedeutung der Logistik für die Unternehmen nicht gerecht. So ist etwa der große Erfolg von Apple zwar primär auf die Produkte des Unternehmens, wesentlich aber auch auf seine professionelle Logistik zurückzuführen. Sie ermöglicht es Apple, neue Geräte in kürzester Zeit in die Märkte einzuführen. Ein zweites Beispiel: Amazon ordnet sich - wie die aktuellen Tarifstreitigkeiten zeigen - selbst der Gruppe der Logistikunternehmen zu. Ähnliches gilt auch für viele Internet-Start-ups.

Logistik geht heute weit über Transportieren und Lagern hinaus. Als Supply Chain Management verbindet sie Märkte über Wertschöpfungsstufen hinweg. Sie macht die hohe Verflechtung globaler Wirtschaft erst möglich.

Warum kümmern sich dann Controller so wenig um eine so wichtige Funktion? Zwei Gründe könnten hierfür maßgeblich sein. Erstens, die Logistik besitzt eine staubige Vergangenheit und wird lediglich mit Transportieren und Lagern in Zusammenhang gebracht. Ihre gewandelte Bedeutung wurde lange Zeit in den Unternehmen nicht erkannt. Auch viele Controller haben sie unterschätzt und ihren Fokus eher auf andere Bereiche gerichtet - generell ist die Aufmerksamkeit, die ein Unternehmensbereich im Controlling genießt, ein guter Indikator für seinen Stellenwert im Unternehmen. Zweitens, die hauptsächlichen Steuerungsgrößen der Logistik wie etwa Servicegrade oder Durchlaufzeiten sind nicht-finanzieller Art. Controller tun sich

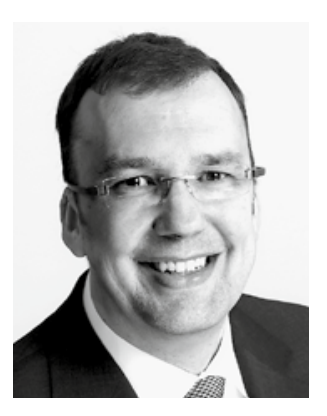

Utz Schäffer

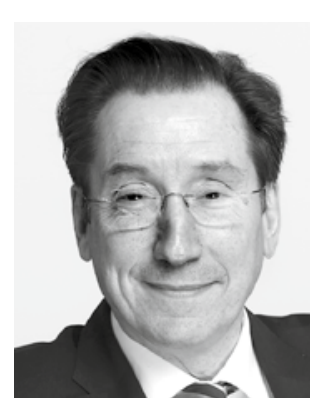

Jürgen Weber aber - trotz aller Bekanntheit der Balanced Scorecard und neuer Begriffe wie Performance Management - noch immer mit nicht-finanziellen Größen schwer. Um die Logistik zu steuern, müssen die Controller zum einen das Geschäft verstehen (der Business Partner lässt grüßen), zum anderen müssen sie bereit sein, sehr viel Zeit in die Definition, Standardisierung und Qualitätssicherung von nicht-finanziellen Daten zu investieren. Schon im Bereich der finanziellen Steuerungsgrößen war es nicht einfach, die Position einer „single source of truth“ aufzubauen. Im Bereich der „non financials“ ist das noch deutlich mühsamer.

Dennoch sollten Controller den Weg gehen. Diverse empirische Studien zeigen, dass die Verbindung finanzieller und nicht-finanzieller Ziele sowie vor- und nachlaufender Steuerungsgrößen eine bessere Steuerung ermöglicht und Unternehmen erfolgreicher macht. Die Logistik stärker ins Blickfeld zu nehmen, wird also nicht nur der hohen Bedeutung der Funktion gerecht, sondern hilft auch insgesamt, die Steuerung des Unternehmens zu verbessern.

Viel Spaß bei der Lektüre wünschen Ihnen

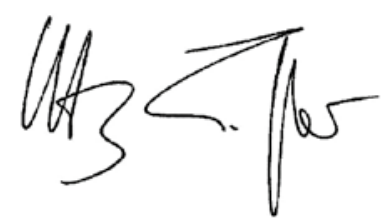

Utz Schäffer

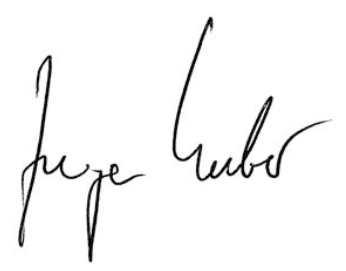

Jürgen Weber 